\title{
Molecular techniques for detecting food adulteration
}

\author{
EWA HABZA-KOWALSKA, MAŁGORZATA GRELA*, \\ MAGDALENA GRYZIŃSKA**, PIOTR LISTOS*
}

\author{
Department of Biochemistry and Food Chemistry, Faculty of Food Science and Biotechnology, \\ University of Life Sciences in Lublin, Skromna 8, 20-704 Lublin, Poland \\ *Department and Clinic of Animal Internal Diseases, Faculty of Veterinary Medicine, \\ University of Life Sciences in Lublin, Głęboka 30, 20-612 Lublin, Poland \\ **Institute of Biological Basis of Animal Production, Faculty of Biology and Animal Breeding and Bioeconomy, \\ University of Life Sciences in Lublin, Akademicka 13, 20-950 Lublin, Poland
}

\section{Habza-Kowalska E., Grela M., Gryzińska M., Listos P. \\ Molecular techniques for detecting food adulteration \\ Summary}

Food adulteration means that substances have been added to food that change its composition and reduce its nutritional value. Food adulteration also includes giving a product a misleading name, providing false information on its composition, date of production or expiry date, and any other incorrect labelling. Numerous cases of food adulteration have been recorded in many countries, including Poland. This has led to the creation of a new field of science, known as 'green criminology', to combat violations of food law. Over the years, new techniques for identifying food adulterations have been developed. Originally, these were sensory techniques, which proved unreliable. Later, physical analysis of the product was performed on the basis of information on the label and microscopic examination. Later methods, based on identification of lipids and proteins, were also unreliable due to biochemical changes during processing. These problems prompted scientists to become interested in the potential of DNA testing. Due the stability of DNA and the universal applicability of DNA-based methods to all cells, they are ideal for use in practice. Currently, the most reliable test for detecting food adulteration is PCR, as it is a highly sensitive and specific technique.

Keywords: food adulteration, molecular techniques, detection of adulterations, green criminology

Food adulteration has been practiced for centuries, but the issue has only recently come under closer examination. This may be due to the fact that until recently the scale of this phenomenon was relatively insignificant. Such offences involve mainly the sale and distribution of food products that are not in compliance with the law. The products most susceptible to adulteration are meat and meat products, milk and dairy products, confectionery products, beverages (including alcoholic beverages), fruits, vegetables, and all types of organ meats (20), as well as oils, honey, coffee and tea. The replacement of one meat species with another in the meat processing industry is also a serious offence (27).

An adulterated product is one to which substances have been added that alter its composition or reduce its nutritional value, or one in which an ingredient has been omitted or reduced, causing a decrease in its nutritional value or other valuable properties of the product. Food adulteration may also involve the use of processes or treatments that mask the actual composition of the product or give it characteristics that falsely indicate adequate quality. Food adulteration includes not only operations on the product itself, but also giving the product a misleading name, providing false information on its composition, date or place of production, or expiry date, and any other incorrect labelling. Food is adulterated mainly to maximize the producer's profit by reducing the cost of production, to increase the producer's competitiveness with other producers offering similar products at higher prices, and to conceal the actual quality of the product, which deviates from quality standards. A less common reason is to conceal irregularities in technological processes (29).

Issues involving food adulteration are dealt with by a branch of criminology known as 'green criminology', which investigates the activities of international food corporations and methods by which they deceive their consumers. Green criminologists also examine the negative impact of the illegal practices of these corporations on human health and the natural environment (20). 
An example of a serious violation on an international scale was a scandal in China in 2013, where a gang of over 900 members distributed meat from rats, martens, foxes and mink as lamb. The actual origin of the meat was effectively concealed by adding gelatine and by appropriate treatment. The abbreviation MSM (mechanically separated meat) is increasingly seen among the ingredients listed on labels of various types of meat products. MSM is a paste of meat and fat obtained from animal elements. It contains much more fat than actual meat and is also susceptible to oxidation, which necessitates the use of antioxidants in the production process. A frequent violation is the exceedance of the permissible content of MSM in meat products (20).

It can be concluded from the above examples that food adulteration is a common problem throughout the world. Therefore, research on detecting such practices should be supported and intensified to prevent the spread of this phenomenon.

\section{Development of techniques for detecting food adulteration}

The first methods of food identification were based on morphological characteristics, such as taste, colour, smell, appearance and shape. In ancient times, the most important indicators were weight and volume. These means of identifying adulterations in food were very unreliable because they were based on physical inspection alone. For example, physical examination of the quality and purity of honey was carried out by specialized honey inspectors. In the $19^{\text {th }}$ century, inspection methods were expanded to include identification with analytical scales and microscopes (21). Germany and other European countries still use this type of testing to detect materials of plant and animal origin in food and feed. However, microscopic methods are frequently incapable of determining the species origin of food or feed components. Therefore, many analytical tools based on lipid, protein and nucleic acid biomarkers have been developed. Lipid and protein biomarkers are currently falling out of use, because protein biomarkers are easily denatured and the amount of lipids is significantly modified during technological processing (1).

Physical identification of food consists mainly in checking the ingredients listed on the label and performing microscopic analysis. The main disadvantage of labels is that there is no scientific verification of the composition given on the label, but only the word of the manufacturer. Incorrect labels are not verified, and labels may be lost during transport or storage. Microscopic analysis entails the risk of incorrect identification of the sample because of changes in the product during processing. Samples can also be lost, and microscopic analysis is costly, due to the need for professional microscopes, as well as time-consuming and difficult (2).

Identification of lipids and volatile organic compounds is another method of detecting food adul- teration. For detection of lipids, lipid biomarkers are used. Briefly, the analysis consists in identification of the species based on analysis of the location of fatty acids in triacylglycerol (TAG) and 2-monoacylglycerol (2-MAG) molecules. Identification tools include Fourier-transform infrared spectroscopy (FTIR), gas chromatography-mass spectrometry (GC-MS) and principal component analysis (PCA). The main disadvantage of these techniques is that the result is less reliable if the lipid acids and the amount and type of lipid are modified in the course of technological treatments. Correct conclusions require a complicated statistical analysis. This type of research is also expensive due to the use of costly equipment and the need to employ qualified professionals (23). Identification of volatile organic compounds is based on the use of gas chromatography, mass spectrometry and spectroscopy.

Proteins can be identified by HPLC (high performance liquid chromatography), 2D electrophoresis, isoelectric focusing, ELISA, and Western blotting. HPLC is used to detect and quantify species-specific protein biomarkers, such as histidine. This technique cannot be used to determine the source of animal proteins. Isoelectric focusing can provide information on the habitat, age and health status of animals based on the analysis of structural proteins, such as actin, myosin or tropomyosin. 2D electrophoresis can be used to analyse a mixture of one hundred proteins. Both techniques are very costly and labour-intensive and require specialist skills. Moreover, they cannot be performed on very complex mixtures (25). The ELISA test, an enzyme immunoassay, is used to detect species-specific antibodies and antigens. It can identify both the source of tissues and the type of animal proteins. A disadvantage of this test is its high sensitivity and low specificity, which means that the result requires confirmation (16). The Western blotting technique can successfully identify proteins and map proteins expressed in the cell cycle. However, it also has a number of disadvantages, such as the impossibility of quantitative analysis and the need to use primary antibodies directed against the protein of interest. It also requires qualified staff to conduct the Western blotting (18).

Meat biosensors and biochips, such as DNA sensors and DNA microarray chips, are also used to detect food adulteration. DNA sensors are portable devices used to detect specific hybridization through changes in optical or electrochemical properties. They can also identify short DNA molecules that have survived processing under extreme conditions. However, it is not possible to amplify copies, because this reduces the sensitivity of DNA sensors. DNA microarray chips, like sensors, are portable devices that can identify hundreds or even thousands of objects through changes in optical or electrochemical properties. Short DNA molecules that have survived under extreme conditions can be identified as well. The disadvantages of microarray chips include the inability to amplify a number of 
copies, which would reduce sensitivity. Moreover, it is impossible to obtain quantitative information (13).

Due to the numerous problems associated with the use of techniques based on proteins and lipids, scientists have become interested in the development of techniques involving detection of nucleic acids (32). Due to the high stability of DNA and universal application to all cells, DNA-based methods are ideal for use in practice. Polymerase chain reaction (PCR), DNA barcoding, nucleic acid biosensors and chips have been proposed for species identification of meat. PCR has also become widely used in biomedicine, agriculture and judicial systems to identify criminals, establish paternity, or determine the origin of diseases or species of meat. These numerous applications are possible because the method is so sensitive that even a single copy of a gene can be amplified, even from a complicated array. In the food industry, PCR is used to determine the level of contamination of processed meat, which has opened new perspectives for the food business (8). Conventional PCR techniques using electrophoresis have been replaced by automated real-time PCR, in which reactions are performed using fluorescent dyes, such as SYBR Green, EvaGreen and TaqMan probes. Multiplex PCR, capable of detecting many species in a single reaction, is one of the newest techniques in the PCR technology (10).

An infinite number of copies of a single DNA molecule can be created using the PCR technique, even when the sample contains many different DNA molecules. It is used to amplify a specific DNA sequence located between known regions (primers) in a double strand of DNA. The polymerase chain reaction can be used to amplify both double-stranded and singlestranded DNA. Amplification of a DNA fragment, followed by agarose gel electrophoresis to verify the size of the fragment, is the simplest strategy for assessing whether a given animal species is present in a meat product (6). Additional confirmation of PCR products can be obtained by the sequencing of DNA amplicons, restriction fragment length polymorphism analysis (PCR-RFLP), real-time PCR and single-strand conformation polymorphism analysis (PCR-SSCP). The techniques used to obtain the product include amplified fragment length polymorphism analysis (AFLP), analysis of inter-simple sequence repeat polymorphism (ISSR), analysis of short-tandem repeat polymorphisms (SSR) and amplification of multiple templates during a single PCR reaction (Multiplex PCR) (30).

RAPD was the first PCR-based technique, and it is currently the simplest one. Randomly chosen short primers (about $10 \mathrm{bp}$ ) are used to amplify DNA in the genome. The final amplification product is generated in the flanking region in the appropriate orientation. RAPD products are usually visualized on agarose gel with addition of ethidium bromide (15). This method makes it possible to obtain a larger number of products by reproducing unspecified fragments of template DNA. It does not require prior knowledge of the individual's genome. The main disadvantage of this method is that it is difficult to obtain reproducible results. The reaction conditions must be strictly defined (temperature, number of cycles and concentration of reagents). It is very important that the quality of the initial DNA is high and that repeatable RAPD profiles can be obtained. This technique is limited in the case of finely minced cured meat, in which there is a large amount of degraded nucleic acids. In addition, due to the non-specific nature of the PCR reaction, the RAPD method cannot be applied to cured meats with many admixtures from different animal species. Thus, in the case of species identification of animals, RAPD can only be used for rapid qualitative analysis, and the samples must be tested each time according to strictly defined standards (6).

The sequencing of fragments amplified in PCR provides the most information and does not require the use of any enzymes. A wide range of plant and animal species can be identified using one pair of primers. Further analysis of PCR amplicons can be used for interspecific and intraspecific identification of DNA in finished products. This makes it possible to distinguish even between closely related species. The markers used most frequently to identify species by sequencing are $12 \mathrm{~S}$ and $16 \mathrm{~S}$ rRNA, which is due to their sufficient level of mutation and the high availability of mitochondrial cytochrome b gene sequences in databases. Owing to rapid technological progress, DNA sequencing is becoming cheaper and more reliable and uses increasingly integrated tools for species identification (9).

RFLP (Restriction Fragment Length Polymorphism) is of particular importance in identifying the origin of meat. The technique uses sequence changes occurring in specific regions of DNA, and it can distinguish even between closely related species. This is possible due to the digestion of selected DNA fragments with appropriate restriction enzymes (6). The main advantages of PCR-RFLP are its low cost and simplicity, so it can be used for large-scale routine testing. PCR-RFLP cannot be used with meat that has been subjected to treatment that destroys DNA, because the amplification of large DNA fragments, which are generally required when using restriction enzymes, is limited by thermal degradation of DNA. PCR-RFLP is not suitable for analysing meats with many admixtures of different animal species, as the results may show a combination of diverse samples representing all possible species contained in the sample. For analysis of highly degraded or mixed species in a meat product, a good solution is to use primers specific for each species (26).

Real-time PCR can detect even trace amounts of various plant and animal species in products of complex composition. This technique is considered the most promising molecular tool for identifying different species in food products (11). Real-time PCR is a pro- 
cess in which the formation of amplification products is directly monitored during each amplification cycle, and the products can be directly measured when the PCR reaction is in the exponential phase and none of the reaction components is limited. Quantitative analysis is possible at an early stage of the reaction, which is more accurate than the final analysis on an agarose or polyacrylamide gel after electrophoresis. Real-time data is collected using fluorescent molecules whose fluorescence intensity is strongly correlated with the content of PCR products. The main advantages of real-time PCR include the possibility of quantitative measurements at an early stage of the PCR process and identification of the origin of DNA. There is also no need for electrophoresis, because the data are read owing to fluorescence. It is very fast, and many samples can be analysed within a short time. However, the use of this technique may be limited by the cost of specific fluorescent probes (5).

PCR-SSCP (single-strand conformation polymorphism) is a sensitive method for detecting point changes in an amplified DNA fragment, from one hundred to several hundred nucleotides in length. It is based on the fact that a DNA fragment with a mutation deviates in its conformation from a fragment without this mutation, and therefore it migrates differently during polyacrylamide gel electrophoresis (28). Results obtained by Bania et al. (2001) showed that the method can be used to analyse adulterations of dairy products (3).

AFLP is a technique used to detect polymorphisms and to analyse the genetic diversity of species, especially in combination with devices for fluorescent DNA sequencing. It is commonly used for assessment of genetic diversity and for phylogenetic analysis in poultry (14).

The ISSR technique (inter-simple sequence repeats) involves the amplification of regions between adjacent microsatellites with opposite orientation. ISSR does not require prior knowledge of DNA sequences. ISSR technology is cheaper, simpler and faster than other methods and can give different genetic profiles when one primer is used for genome analysis. In recent years, this technique has been used to test some types of seafood, and the results have shown that ISSR amplification can be used to examine intra-species and interspecies variability in marine fauna populations (31).

One of the uses of SSR (analysis of short-tandem repeat polymorphisms) is to study relationships between genotypes at the intraspecific level. These are repeats of short nucleotide sequences, usually of six nucleotides or fewer, known as microsatellites. Their distribution in the eukaryotic genome is random. Polymorphisms can be easily detected, e.g. with sequencing gels. These polymorphisms are the result of polymerase slippage during DNA replication or unequal crossing-over. The advantages of SSR include the fact that microsatellites make it possible to identify multiple alleles in a single locus. They are also evenly distributed throughout the genome and provide a more detailed insight into mitochondrial DNA, inherited from the mother, owing to the high rate of mutation. SSR is highly specific, repeatable and inexpensive. It requires only a small amount of DNA, which can be of medium quality, and the analysis can be automated. With the rapid development of DNA isolation technology, it has become possible to identify loci in highly degraded, ancient DNA, for which traditional procedures are ineffective (15). The method has been used, for example, to detect adulterations in wines and musts (22).

In classical PCR, a species-specific primer pair is used to amplify DNA fragments that are subsequently detected on agarose gel. The sequence can be further confirmed by amplicon sequencing, restriction digestion and RAPD analysis. Then, the DNA of one species is amplified by PCR. Several PCR reactions are needed to detect several species, which is time-consuming and costly (12). The multiplex PCR method makes it possible to carry out DNA amplification of different species in one reaction. The multiplex reaction was developed in 1988 in order to analyse gene deletion in Duchenne muscular dystrophy. Since then, multiplex PCR has attracted the attention of many scientists as an outstanding technique for detection of multiple objects in a single analysis. The success of the multiplex PCR reaction depends on whether the primers chosen for the reaction can selectively attach to the right DNA strands in a single reaction under specific reaction conditions and with a specific sample volume. Thus, the reaction requires a complicated construction of primers specific to different species and rigorous conditions for optimizing the reaction. In fact, primer design is the most important and critical stage in the development of the multiplex PCR system. This is due to numerous difficulties in optimizing the melting, annealing, and primer extension temperatures, as well as in preventing the formation of secondary structures and dimers. The effectiveness of PCR may be reduced by even a small deviation in the primer melting point. Even a $1 \%$ base mismatch in the primer-binding regions reduces the primer melting point by $1-1.5^{\circ} \mathrm{C}(1)$. Interspecific hypervariable and intraspecific conserved DNA regions are typically selected for primer design (2).

Multiplex end-point PCR is very similar to the archetypal version. Multiple primer pairs are used to amplify multiple oligonucleotides in a single reaction, and the products are identified on agarose gel on the basis of differences in amplicon length. Before starting the reaction, the specificity of the primers and samples should be tested using conventional PCR and PCRRFLP. In addition, species specificity is verified using in silico and in vitro tests.

Multiplex PCR has been recognized as a reliable, relatively inexpensive and sensitive method for identifying meat species. In 1999, Matsunaga's research team became the first to begin developing detection of meat species by this method. They used a common 
forward primer but different reverse primers for the mitochondrial cytochrome $b$ gene. Thus they were able to identify five species of meat: goat, cattle, sheep, pig and horse. This technique has also achieved very good results in testing industrially processed meat. The most commonly used genes are mitochondrial cytochrome b, ribosomal 12S RNA, 16S RNA, D-loop, tRNA, and ATPase6/ATPase8. In addition, 18S rRNA, SINEs (short interspersed nuclear elements) and LINEs (long interspersed nuclear elements) are quite widely used (1).

Because of the inadequate efficiency of multiplex end-point PCR in terms of quantitative information about the genetic material, scientists have developed multiplex real-time PCR (7). This technique effectively eliminates the limitations of end-point PCR through direct monitoring of individual amplification cycles. The final result is a quantitative result based on measurement of the fluorescence intensity of a nonspecific fluorescent dye, such as SYBR Green (24) or sequence-specific DNA probes called TaqMan. Realtime PCR has some limitations: for example, the cost of this method is much higher than that of end-point PCR, and ready kits and standardized methods are not available for all types of genes (4). Both simplex and multiplex real-time PCR have been used to identify meat species.

The most important parameters in the real-time PCR system are the threshold cycle $(\mathrm{Ct})$ and the quantification cycle $(\mathrm{Cq})$, which is defined as the cycle in which fluorescence is detected at a statistically significant level above the baseline signal or the background signal. The $\mathrm{Ct}$ value is inversely correlated with the logarithmic value of the initial number of copies and is above the baseline in the exponential phase. When optimizing the PCR reaction, it is necessary to find the lowest $\mathrm{Ct}$ value and the highest final fluorescence intensity, which can be obtained using appropriate concentrations of the primers and probes (8). Early detection indicates a high level of occurrence of target copies of template DNA in the sample. The detection limits of real-time PCR are variable, but sufficient to identify adulterations in the test material (17).

As already mentioned, fluorescent dyes, such as CYBR Green and TaqMan, are widely used for detection in real-time PCR. CYBR Green binds nonspecifically to the minor groove of the double helix of DNA found in the reaction mixture. The fluorescence intensity increases with the synthesis of doublestranded amplicons (7). This makes SYBR Green dye simple and cost-effective. It is not dependent on the complex structure of the probe, but requires a thorough analysis of the melting curve (5). The simplicity and cost-effectiveness of using this pigment prompted scientists to utilize SYBR Green in real-time PCR to detect cattle, horses, deer, pork, chickens, ostriches and various species of tuna (1). The sensitivity of the reaction when this dye is used is very high, sufficient to detect even trace amounts of impurities in test material, at a level of $0.000004 \mathrm{ng}$ DNA (5). Despite its advantages, SYBR Green dye has certain limitations in species identification. At high concentrations, it inhibits the course of PCR. To avoid this limitation, scientists have proposed the use of EvaGreen, an alternative intercalating dye that does not inhibit PCR amplification and can be used at higher concentrations, so that a stronger signal for melting curve analysis is obtained. In addition, it is more stable than SYBR Green and better withstands unfavourable conditions, while increasing the sensitivity of the reaction. EvaGreen has been successfully used for simplex and multiplex real-time PCR to test hare meat and to detect beef and soy in processed sausages. The TaqMan probe, which binds to the complementary sequence between the primers and is cleaved by the $5^{\prime}$ exonuclease activity of Taq DNA polymerase, is a better choice than SYBR Green or EvaGreen (17). Nearly all meat products of importance for industry can be identified using real-time PCR with the TaqMan probe. Real-time PCR based on the TaqMan probe for identification of meat species can be designed in several ways: a single probe for detecting a single species, multiple probes with one quencher and reporter pair for detection of multiple species, or multiple probes with different quencher and reporter combinations for each species.

There have already been reports of family-specific real-time PCR using the TaqMan probe to detect several species of a given family, for example, of mammals, birds or fish. However, family-specific probe design requires some base modifications in order to be specific to different species from the same family. Although the TaqMan probe is highly specific and emits a strong signal in relation to the background noise, probe design is quite difficult. The protocol is highly restrictive and requires continuous monitoring of the melting temperature and the content of GC pairs and secondary structures, and especially monitoring for hairpin structure and the primer dimer problem (4). The melting temperature for the probe must be $8-10^{\circ} \mathrm{C}$ higher than the melting point of the primers (10). In addition to the TaqMan probe, there are several molecular probes that provide higher specificity. These probes are based on molecular markers and scorpion probes. The sensitivity of the former may play a major role in species identification in the future. The role of the scorpion probe in species identification has not yet been described, most likely due to its complex structure (7).

The problem of food adulteration is common and it affects the entire world. There is a need for restrictive regulations that businesses will have to adhere to and for enforcement of ethical behaviour in food production. There are many techniques that can be used for detecting food adulterations, with particular emphasis on meat products. Among the techniques based on DNA analysis, it is possible to select methods that meet all the requirements for use in industrial practice. 


\section{References}

1. Ali M. E., Razzak M. A., Hamid A. S. B.: Multiplex PCR in species authentication: probability and prospects - a review. Food Anal. Method 2014, 7, 1933-1949.

2. Ballin N. Z., Vogensen F. K., Karlsson A. H.: Species determination - can we detect and quantify meat adulteration? Meat Sci. 2009, 83, 165-174.

3. Bania J., Ugorski M., Polanowski A., Adamczyk E.: Application of polymerase chain reaction for detection of goats' milk adulteration by milk of cow. Journal of Dairy Research 2001, 68, 333-336.

4. Cammà C., Di Domenico M., Monaco F.: Development and validation of fast real-time PCR assays for species identification in raw and cooked meat mixtures. Food Control 2012, 23, 400-404.

5. Fajardo V., Gonzalez I., Martin I., Rojas M., Hernandez P. E., Garcia T., Martin R.: Real-time PCR for detection and quantification of red deer (Cervus elaphus), fallow deer (Dama dama), and roe deer (Capreolus Capreolus) in meat mixtures. Meat Sci. 2008, 79, 289-298.

6. Fajardo V., Gonzáles I., Rojas M., García T., Martín R.: A review of current PCR-based methodologies for the authentication of meats from game animal species. Trends Food Sci. Technol. 2010, 21, 408-421.

7. Hazim M. M. Y., Mustafa S., Cheman Y. B., Omar A. R., Mokhtar N. F. K. Detection of raw pork targeting porcine-specific mitochondrial cytochrome $b$ gene by molecular beacon probe real-time polymerase chain reaction. Food Anal. Method. vol. 5 2012, 422-429.

8. Herrero B., Vieites J. M., Espiñeira M.: Authentication of Atlantic salmon (Salmo Salar) using real-time PCR. Food Chem. 2011, 127, 1268-1272.

9. Karlsson A. O., Holmlund G.: Identification of mammal species using speciesspecific DNA pyrosequencing. Forensic Sci. Int. 2007, 173, 16-20.

10. Kesmen Z., Celebi Y., Güllüce A., Yetim H.: Detection of seagull meat in meat mixtures using real-time PCR analysis. Food Control 2013, 34, 47-49.

11. Koppel R., Zimmerli F., Breitenmoser A.: Heptaplex real-time PCR for the identification and quantification of DNA from beef, pork, chicken, turkey, horse meat, sheep (mutton) and goat. Eur. Food Res. Technol. 2009, 230, 125-133

12. Köppel R., Ruf J., Rentsch J.: Multiplex real-time PCR for the detection and quantification of DNA from beef, pork, horse and sheep. Eur. Food Res. Technol. 2011, 232, 151-155.

13. Kowalczyk M., Zawadzka E., Jakubczak A., Gryzińska M., Szewczuk D. Molecular Markers Used in Human and Animal Forensic Genetics. Med. Sci. Law. 2018, 58, 201-209.

14. Kumar V., Kumar Shukla S., Kumar Singh S., Goyal G., Mathew J., Sharma D. Genetic diversity and phylogenic relationship analysis between red jungle fowl and domestic chicken using AFLP markers. Japan Poult. Sci. As. 2015, 52, 94-100.

15. Mawgood A. L. A.: DNA based techniques for studying genetic diversity. Genet. Diversity Microorg. vol. 4, 2012, 97.

16. Mecca J. N., Meireles R., De Andrade H. F. Jr.: Quality control of toxoplasma gondii in meat packages: standardization of an ELISA test and its use for detection in rabbit meat cuts. Meat Sci. 2011, 88, 584-589.
17. Mohamad N. A., El Sheikha A. F., Mustafa S., Mokhtar N. F. K.: Comparison of gene nature used in real-time PCR for porcine identification and quantification: a review. Food Res. Int. 2013, 50, 330-338.

18. Mollica J. P., Oakhill J. S., Lamb G. D., Murphy R. M.: Are genuine changes in protein expression being overlooked? Reassessing western blotting. Anal. Biochem. 2009, 386, 270-275.

19. Nurjuliana M., Cheman Y. B., Mat Hashim D., Mohamed A. K.: Rapid identification of pork for halal authentication using the electronic nose and gas chromatography mass spectrometer with headspace analyzer. Meat Sci. 2011, 88, 638-644.

20. Pływaczewski W., Płocki R.: Nielegalny rynek żywności. Skala zjawiska i możliwości przeciwdziałania. Wydawnictwo Wyższej Szkoły Policji w Szczytnie. Szczytno 2013, p. 12-15.

21. Raamsdonk L. W. D. Van, Holst C. von, Baeten V., Berben G., Boix A., de Jong J.: New developments in the detection and identification of processed animal proteins in feeds. Anim. Feed Sci. Technol. 2007, 133, 63-83.

22. Rienzo di V., Fanelli V., Miazzi M. M., Savino V., Pasqualone A., Summo C., Giannini P., Sabetta W., Montemurro C.: A reliable analytical procedure to discover table grape DNA adulteration in industrial wines and musts. Acta Hortic. 2017, 1188, 365-370.

23. Rohman A., Sismindari, Erwanto Y., Cheman Y. B.: Analysis of pork adulteration in beef meatball using Fourier transform infrared (FTIR) spectroscopy. Meat Sci. 2011, 88, 91-95

24. Soares S., Amaral J. S., Oliveira M. B., Mafra I.: A Sybr Green realtime PCR assay to detect and quantify pork meat in processed poultry meat products. Meat Sci. 2013, 94, 115-120.

25. Spiegel M. Van der, Fels-Klerx H. J. Van der, Sterrenburg P., Ruth S. M. van, Scholtens-Toma I. M. J., Kok E. J.: Halal assurance in food supply chains: verification of halal certificates using audits and laboratory analysis. Trends Food Sci Technol. 2012, 27, 109-119.

26. Stirtzel S., Andree S., Seuss-Baum I., Schwagele F.: Authentification of the most common poultry species by means of PCR. Fleischwirtschaft 2007, 87, 86-89.

27. Śmiechowska M.: Autentyczność jako kryterium zapewnienia jakości żywności. Ann. Acad. Med. Gedan. 2013, 43, 176.

28. Tahira T., Kukita Y., Higasa K., Okazaki Y., Yoshinga A., Hayashi K.: Estimation of SNP allele frequencies by SSCP analysis of pooled DNA. Single nucleotide polymorphisms. Methods Protocols 2009, 578, 193-207.

29. Targoński Z., Stój A.: Zafałszowania żywności i metody ich wykrywania Żywn. Nauk. Technol. 2005, 4, 30-40.

30. Tobe S. S., Linacre A. M. T.: A multiplex assay to identify 18 European mammal species from mixtures using the mitochondrial cytochrome $b$ gene. Electrophoresis 2008, 29, 340-347.

31. Tsai-Hsiu CH., Ching-Wen K., Hui-Chin L., Ding-Shi H., Po-Long W.: Genetic diversity of ivory shell (Babylonia Areolata) in Taiwan and identification of species using DNA-based assays. Food Control 2015, 48, 108-116.

32. Ulca P., Balta H., Cagin I., Senyuva H. Z.: Meat species identification and halal authentication using PCR analysis of raw and cooked traditional Turkish foods. Meat Sci. 2013, 94, 280-284.

Corresponding author: Piotr Listos DVM, PhD; ul. Głeboka 30, 20-612 Lublin; e-mail: piotr.listos@up.lublin.pl 